\title{
LA POSITIVIZACIÓN DEL CONCEPTO DE SERVICIO PÚBLICO
}

\author{
BERNARDO SÁNCHEZ PAVÓN \\ Doctor en Derecho por la Universidade da Coruña \\ Letrado de la Junta General de Asturias
}

Fecha de recepción: 30.6.2016

Fecha de aceptación: 8.11.2016

Resumen: El problema de los "fallos del mercado" y la intervención del Estado en la provisión de bienes han sido y seguirán siendo objeto de encendidos debates en los campos de la Economía, el Derecho y la Ciencia Política.

Para el Derecho público, resulta imprescindible fijar con precisión lo que debe entenderse por funciones del Estado, servicio público, servicios nacionalizados y servicios de interés general. La determinación de sus contornos no es sólo tarea propia del Derecho administrativo, sino del Derecho constitucional.

Palabras clave: funciones del Estado, servicio público, servicios nacionalizados, nacionalizaciones, regulación.

Abstract: The problem of the "market failures" and the State intervention in public goods provision are object of doctrinal debates in the fields of Economy, Law and Political Science.

For the public law, it is necessary to specify the meaning of State functions, public service, nationalised services and services of general economic interest. The determination of theirs borders is not only a task of the administrative law, but also the constitutional law.

Key Words: State functions, public services, nationalised services, nationalisations, public regulation 
SUMARIO: I. INTERVENCIÓN PÚBLICA EN LA ACTIVIDAD ECONÓMICA, ESTADO MÍNIMO Y REGULACIÓN. 1. Fundamentación económica de la intervención estatal. 2. El apostolado por el "Estado mínimo". 3. La regulación. La regulación. II. SERVICIO PÚBLICO, FUNCIONES DEL ESTADO Y NACIONALIZACIONES. 1. La azarosa polisemia del término "servicio público". 2. Funciones del estado y servicios públicos: constitucionalidad versus legalidad. 3. Diferencias entre "nacionalización" y "declaración de servicio público". 4. Funciones del estado, servicios públicos y nacionalizaciones. 5. La crisis del servicio público puede ser simple apariencia. III. CONCLUSIONES

\section{INTERVENCIÓN PÚBLICA EN LA ACTIVIDAD ECONÓMICA, ESTADO MÍNIMO Y REGULACIÓN}

\section{Fundamentación económica de la intervención estatal}

La discusión acerca del servicio público también se ha originado en el campo de la economía, especialmente a través del debate doctrinal sobre la "teoría de los bienes públicos, dentro de la cual cabe distinguir dos posturas enfrentadas:

a) Para SAMUELSON un bien público puro cumpliría dos condiciones sine qua non relativas a su oferta y demanda: la no disminución del bien o servicio ofertado como consecuencia de su consumo o prestación y la no exclusión de otros usuarios mediante tales actos ${ }^{1}$. Dicho de otra forma, la demanda del bien no incide en su oferta y, además, resultaría inviable excluir de la condición de beneficiarios a determinadas personas. De ahí que la gestión de los bienes públicos se realice por el Estado y que sean financiados por vía impositiva. En este sentido, STIGLITZ justifica la necesidad de intervención estatal en la producción de este tipo de bienes y servicios sobre la base de que las empresas privadas no suministrarán la cantidad socialmente óptima de bienes públicos puesto que, siendo imposible impedir a ciertas personas utilizar el bien (exclusión), resultará impracticable rentabilizar la actividad ${ }^{2}$. No existiendo coste superior al proporcionar el bien a cada usuario adicional (tras haberlo hecho con el primero), el bienestar social se maximiza al suministrarlo de forma gratuita. Dentro de los bienes públicos se encontrarían la defensa del territorio nacional, la administración de justicia, la seguridad pública, la protección del medio ambiente, el transporte y la energía.

b) En opinión de otros economistas, caso de HOPPE, la propia dinámica evolutiva en la forma de prestación de ciertos servicios públicos sería suficiente para

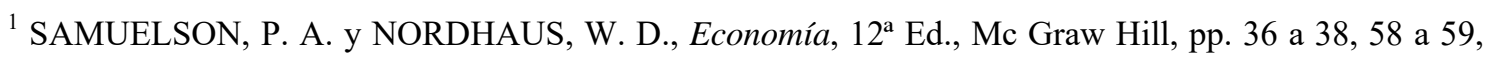
504 a 506 y 865 a 867.MADDALA y MILLER sostienen que este tipo de bienes satisfarían otra condición: la no rivalidad entre usuarios. Dado que su consumo no implica una menor disponibilidad del bien para otros usuarios, no existe competencia entre usuarios actuales y potenciales. Vide MADDALA, G.S. y MILLER, E., Microeconomía, Ed. McGraw-Hill, México, 1996.

${ }^{2}$ STIGLITZ, J. E., La economía del sector público, 3ª ed., Antoni Bosch, 2000, pp. 149 a 178.
} 
resquebrajar los cimientos de la propuesta de SAMUELSON ${ }^{3}$. La experiencia práctica demostraría que los bienes públicos pueden ser adecuadamente producidos como bienes privados (hasta la propia defensa nacional admitiría ser confiada a otros Estados). Por otra parte, el mencionado autor considera que del hecho de que el Estado tenga que proveer como bienes públicos aquellos que de otro modo nadie produciría no cabe inferir, necesariamente, que deban ser producidos. De forma similar a lo que KELSEN postuló para el Derecho ${ }^{4}$, HOPPE sostiene que la economía práctica sería una cosa y la moral o ética otra muy distinta.

STIGLITZ propone distinguir entre los "bienes públicos puros", en los que se cumplirían las dos condiciones de no disminución y no exclusión (seguridad nacional), y los "bienes públicos impuros", en los que sólo se daría la no disminución ${ }^{5}$. Esta diferenciación sería crucial para fijar los difusos límites entre la acción pública y la privada en la economía: El suministro de la mayor parte de los bienes públicos puros corresponderá al Estado, aunque es factible la participación privada en casos excepcionales.

Para ilustrar acerca de las diferencias, podemos acudir a la caracterización de las infraestructuras del transporte como bienes públicos, materia que ha sido singularmente debatida dentro la doctrina económica. SAMUELSON incluyó el transporte dentro de los bienes públicos, pero ¿Podría considerarse como tal semper et ubique una carretera? La respuesta no es tan sencilla ni puede ser categórica. STIGLITZ razona que no es lo mismo una carretera congestionada que otra que no lo esté. En este último caso, el coste marginal de su utilización por parte de un usuario adicional es mínimo o nulo y la exclusión de un eventual free-rider (usuario no dispuesto a pagar) puede resultar desproporcionada (piénsese en los costes organizativos y de funcionamiento que supondría establecer un peaje); en definitiva, una carretera no congestionada es un bien público impuro (cumple con la regla de no disminución, pero no la de exclusión). En cambio, una carretera congestionada sería un caso de una bien muy próximo a la categoría de los bienes privados, pues la utilización de la misma por un usuario adicional puede significar un elevado coste marginal social y la exclusión no resultaría tan desventajosa.

La conclusión que cabe extraer de todo ello es que un mismo bien puede estar más o menos cerca de la condición de público o privado según las circunstancias contextuales. En esto parecen concordar tanto STIGLITZ como DUGUIT: la consideración de una actividad como servicio público es una decisión que depende de la situación concreta, del momento histórico en el que deba decidirse al respecto.

\footnotetext{
${ }^{3}$ HOPPE, H., "Falacias de la teoría de los bienes públicos y la producción de seguridad", en Procesos de Mercado, $\mathrm{n}^{\circ} 1,2007$, pp. 229 a 256.

${ }^{4}$ Sostuvo KELSEN que una "Teoría pura del Derecho" exigiría de una ciencia que tenga por único objeto al Derecho e ignora todo lo que no responda estrictamente a su definición. El principio fundamental de su método es, pues, eliminar de la Ciencia del Derecho todos los elementos que le son extraños; entre otros, la moral. Vide KELSEN, H., Teoría pura del Derecho, Universitaria de Buenos Aires, 1989, pp. 15 y sigs.

${ }^{5}$ MADDALA y MILLER sugieren diferenciar entre los "bienes públicos puros" (defensa nacional, orden público) y "bienes que se encuentran entre los bienes públicos puros y los bienes privados" (educación, medio ambiente o transporte).
} 
La noción de "régimen político", como han señalado ALZAGA y OLLERO, se acuña a partir de la revolución francesa de 1789, en tanto en cuanto el nuevo orden político e institucional se construye en contraposición al "antiguo régimen". El régimen político (régime politique) ha sido definido por DUVERGER como la forma que toma en un grupo social dado la distinción entre gobernantes y gobernados ${ }^{6} \mathrm{y}$ por QUERMONNE como el conjunto de elementos de orden ideológico, institucional y sociológico que concurren a formar el gobierno de un país durante un periodo de tiempo determinado ${ }^{7}$. Aun resultando más sugerente la propuesta de QUERMONNE, todavía puede resultar limitada para que resulte operativa. Por ello, resultaría más conveniente acudir al concepto de "sistema político" (political system) adoptada por la Ciencia Política norteamericana y popularizada por EASTON y POWELL. El sistema político, según estos autores, englobaría -además de las instituciones políticas y de las estructuras sociales y económicas- el sistema de valores (religiosos, morales, culturales), el peso de la tradición y las ideologías (dominantes y minoritarias) ${ }^{8}$.

Partiendo de las anteriores definiciones, los datos históricos evidencian que la participación del Estado en la economía no ha dependido tanto del régimen político (democrático o autocrático) como del sistema político, esto es, de la estructura económica (fuertemente influida por las circunstancias del contexto), el esquema de valores presente en la sociedad, el influjo de la tradición y la capacidad para imponerse que tenga la ideología dominante. Bajo un mismo régimen político, el sistema político vigente es lo que determinará la emergencia o no de la intervención estatal.

\section{El apostolado por el "Estado mínimo"}

La defensa y justificación de unas nuevas coordenadas para reorientar lo público y arrumbar el Estado del Bienestar han encontrado el acendrado exponente en el profesor de Harvard ROBERT NOZICK. Sus aportaciones, sintetizadas en Anarquía, estado y utopía, cuestionan los valores y principios sobre los que se fue cimentando el Estado moderno desde su nacimiento en el marco de la Revolución Francesa.

Analizando la Filosofía del Derecho del siglo XX, puede afirmarse que NOZICK es el contrapunto a las propuestas efectuadas por su contemporáneo JOHN RAWLS. Allí donde RAWLS presupone un contrato social como fundamento para una sociedad y un ordenamiento jurídico justos, NOZICK rechaza tal pacto arguyendo que violaría los derechos de quienes no los hubieran suscrito y aboga por un Estado mínimo.

El interés por las aportaciones de NOZICK radica en que su visión peyorativa del Estado se fundamenta en evitar la lesión de los derechos individuales. En ello coincide con una parte del iuspublicismo actual. Para descubrir las ideas centrales del pensamiento de NOZICK, lo mejor son sus propias palabras:

\footnotetext{
${ }^{6}$ En DUVERGER, M., Les Régimes politiques, Presses Universitaires de France, 1948; SCHNERB R. y DUVERGER, M., "Les régimes politiques", en Annales. Économies, Sociétés, Civilisations, vol. 4, n 3, 1949.

${ }^{7}$ QUERMONNE, J. L., Les régimes politiques occidentaux, Éditions du Seuil, 2000.

${ }^{8}$ Vide: EASTON, D., The Political System: An Inquiry Into the State of Political Science, Knopf, 1953 y GABRIEL, A. y POWELL, G., Comparative Politics, a developmental approach, Boston, MA, Little Brown, 1966.
} 
"Los individuos tienen derechos, y hay cosas que ninguna persona o grupo puede hacerles sin violar los derechos. Estos derechos son tan firmes y de tan largo alcance que surge la cuestión de qué pueden hacer el Estado y sus funcionarios, si es que algo pueden. ¿Qué espacio dejan al Estado los derechos individuales? La naturaleza del Estado, sus funciones legítimas y sus justificaciones, si las hay, constituyen el tema central de este libro; una amplia y múltiple variedad de asuntos se entrelazan en el curso de nuestra investigación.

Mis conclusiones principales sobre el Estado son que un Estado mínimo, limitado a las estrechas funciones de protección contra la violencia, el robo y el fraude, de cumplimiento de contratos, etcétera, se justifica; que cualquier Estado más extenso violaría el derecho de las personas de no ser obligadas a hacer ciertas cosas y, por tanto, no se justifica; que el Estado mínimo es inspirador, así como correcto. Dos implicaciones notables son que el Estado no puede usar su aparato coactivo con el propósito de hacer que algunos ciudadanos ayuden a otros o para prohibirle a la gente actividades para su propio bien o protección"9.

La intervención del Estado se encontraría con graves inconvenientes epistémicos:

“[...] ningún acto moralmente compensador puede tener lugar entre nosotros; no hay nada que moralmente prepondere sobre una de nuestras vidas en forma que conduzca a un bien social general superior. No hay ningún sacrificio justificado de alguno de nosotros por los demás. Esta idea básica, a saber: que hay diferentes individuos con vidas separadas y que, por tanto, ninguno puede ser sacrificado por los demás" ${ }^{\text {10 }}$. Más aún, toda propósito de compensación es calificable como una inaceptable agresión: "Frecuentemente se sostiene que el principio de no agresión es un principio apropiado para gobernar las relaciones entre las naciones. ¿Qué diferencia se supone que hay entre individuos soberanos y naciones soberanas, que hace que la agresión sea permisible entre individuos? ¿Por qué pueden los individuos conjuntamente, a través de sus gobiernos, hacer a algunos lo que ninguna nación puede hacer a otra?",11.

A pesar de lo que a priori cupiese suponer, NOZICK no comparte las tesis anarquistas de que el Estado sea intrínsecamente inmoral, dado que el mantenimiento del monopolio del uso de la fuerza implique siempre violar los derechos de los individuos. Muy al contrario, sostiene que aquél surgiría de todas formas, pero partiendo del estado de naturaleza de LOCKE y sin que nadie tratara de provocarlo. Surgiría por un proceso que no necesitaría violar los derechos de nadie ${ }^{12}$, a través de una "mano invisible" 13 que recuerda, en muchos aspectos, a la utilizada por ADAM SMITH, en su célebre An inquiry into the nature and causes of the wealth of nations (1776).

\footnotetext{
${ }^{9}$ NOZICK, R., Anarquía, estado y utopía, Fondo de Cultura Económica, 1990, p. 7.

${ }^{10}$ NOZICK, R., cit., 1990, p. 45.

${ }^{11}$ NOZICK, R., cit., p. 46.

${ }_{12}^{12}$ NOZICK, R., cit., p. 8.

${ }^{13}$ NOZICK, R., cit., p. 32.
} 
El contrapunto a las propuestas de NOZICK puede encontrarse en JOHN RAWLS. Las aportaciones del norteamericano suponen una auténtica concepción de la justicia $^{14}$. Para él, el contrato social de LOCKE, ROUSSEAU y KANT es fruto de un consenso en los principios de justicia aplicables a sociedad futura, alcanzado desde una hipotética "posición originaria" en la que los "principios morales válidos" son aquellos que uno estaría dispuesto a aceptar si se adopta el mismo punto de vista. Partiendo de lo que denomina un "velo de ignorancia" —una ausencia de prejuicios impedientes de una discusión racional-, RAWLS opina que el consenso se lograría en torno a dos principios:

a) Cada persona ha de tener un derecho igual al más amplio sistema total de libertades básicas, compatible con un sistema similar de libertad para todos

b) Las desigualdades económicas y sociales han de estar estructuradas de manera que sean para el mayor beneficio de los menos aventajados y no se impida la posibilidad de acceso de todos los ciudadanos a todos los cargos y funciones

Como puede verse, en la comparativa NOZICK-RAWLS, se enfrentan la "empatía jurídico-constitucional" (denominando así a la disposición a aceptar como principios morales válidos aquéllos que se aceptarían si se adoptase el mismo punto de vista que quien los sostiene) y el individualismo.

En ambos late un claro racionalismo. En uno, la racionalidad se predica del proceso por el que se llega al "Estado mínimo" (los individuos no juegan un papel directo, sólo están dispuestos a defender a ultranza sus derechos y la consecuencia llega como resultado indefectible de la naturaleza de las cosas); en el otro, la razón juega en el origen mismo del pacto, consecuencia de un proceso en el que se consensua un "pacto de mínimos" (los individuos juegan un papel determinante).

Las diferencias entre NOZICK Y RAWLS no son sino una concreción del enfrentamiento entre dos formas de entender la existencia en comunidad: el individualismo y la solidaridad; la mano invisible del mercado y la mano visible del Estado.

Sin ninguna duda, los dos principios básicos de RAWLS no serían aceptables por NOZICK - puesto que garantizarlos requeriría de una agresión-, pero hay que reconocer a este último una impecable coherencia argumental. Lo que resultaría incongruente es proponer conclusiones próximas al individualismo de NOZICK, efectuando, a la vez, solemnes invocaciones a la solidaridad y a la unidad del Estado. Un "Estado mínimo" en su configuración económica ha de aceptar, como contrapartida, que su unidad también será mínima. No estimamos casual que el artículo 2 de la Constitución Española sitúe al lado de la unidad de la nación española el principio de solidaridad entre todas las regiones y nacionalidades. $\mathrm{Ni}$ es posible defender la solidaridad interterritorial (trabazón que garantiza la unidad) rechazando la intersubjetiva ni puede exigirse el compromiso de una parte del territorio nacional con el resto sin exigir lo mismo de los ciudadanos en sus relaciones entre sí.

\footnotetext{
${ }^{14}$ RAWLS, J., A theory of Justice, Oxford, 1971. Acerca de las aportaciones de RAWLS a las relaciones entre justicia y Derecho vide: ATIENZA, M., El sentido del Derecho, Ariel, Barcelona, 2001, pp. 199 y 200 ; SANTIAGO NINO, C., $7^{\text {a }}$ ed., Introducción al análisis del Derecho, Ariel, Barcelona, pp. 408 a 416.
} 
Desde la óptica minarquista (término generalmente atribuido a SAMUEL KONKIN) - es decir, desde el impoluto respeto a la esfera de lo individual - no hay diferencia entre la regulación de una actividad y su prestación directa por el Estado, pues en ambos casos hay imposición y restricción de las libertades. Se dirá que en el primer caso queda en manos de la comunidad la iniciativa, pero esto tampoco es del todo correcto, dado que el Estado no deja de ser (o no debería dejar de serlo) la propia comunidad organizada y no parece erróneo el que determinadas actuaciones de índole técnica sean atribuidas, preferiblemente, a una organización antes que a una desorganización. El ejemplo práctico lo tenemos en el ejercicio de la potestad normativa. El derecho puede crearse a través de la costumbre (comunidad no organizada) o por normas escritas (elaboradas por la comunidad organizada, ora legislativo ora ejecutivo). Las tesis minarquistas exigirían primar la creación de Derecho a través de la costumbre o, como mal menor, un primado absoluto de la iniciativa legislativa popular. Sería lo más ajustado al escrupuloso respeto a las libertades. Aunque Savigny, Puchta y Rousseau se henchirían de gozo bajo sus lápidas, resulta más que justificado dudar sobre la viabilidad jurídica de ese Estado mínimo.

Si damos por buena la reflexión de HELLER, el "Estado social de Derecho" no nació - recuérdese, en el periodo de entreguerras del siglo XX - como consecuencia del insaciable apetito de poder de un Estado devorador de la iniciativa ciudadana, sino que habría aparecido como medio de salvaguardar al Estado de Derecho tanto de la dictadura fascista como de los intereses de los estratos dominantes, quienes habrían convertido a aquél en una idea sin significado o incapaz de encarar los dos frentes en que se despliega la irracionalidad: La irracionalidad del sistema capitalista y la irracionalidad fascista. Para HELLER, la solución a la crisis de la democracia no pasaría por renunciar al Estado de Derecho, sino en dar a éste un contenido económico y social ${ }^{15}$.

El "Estado de bienestar" - término acuñado por BOUDING, como recuerda GARCÍA PELAYO ${ }^{16}$ - parece querer anudarse actualmente a la idea de servicio público. De forma tácita, sería el servicio público el origen de la creación de este concepto y, por tanto, entrado en crisis el servicio público, la lógica consecuencia sería que el propio Welfare State siguiese su mismo rumbo.

La justificación de la limitación de la extensión del Estado sobre la base de los derechos constitucionales del individuo resulta más fácil desde la teoría y las frías operaciones técnico-jurídicas que sobre la realidad y la ética práctica.

La ubicación de un precepto dentro del marco de los derechos y deberes constitucionales y su inmediatez aplicativa sugerirían una hipotética superioridad sobre unos principios rectores de la política social y económica precisados de concreción (sólo podrán ser alegados ante la Jurisdicción ordinaria de acuerdo con lo que dispongan las leyes que los desarrollen), pero el problema surge en el momento de proceder a la elección en términos disyuntivos ¿Prevalece la libertad de empresa frente a la salud de los ciudadanos? ¿El escrupuloso respeto a la economía de mercado está por encima de

\footnotetext{
${ }^{15}$ HELLER, H., "Rechsstaat oder diktatur?", en HELLER, H., Gesammelte Schriften, Leide, 1971, T. II, pp. 443 y sigs. Citado por GARCÍA PELAYO, M., Las transformaciones del Estado contemporáneo, Alianza, $2^{\mathrm{a}}$ ed., 1993, p. 17.

${ }^{16}$ Vide GARCÍA PELAYO, M., Las transformaciones del Estado contemporáneo, Alianza, $2^{\mathrm{a}}$ ed., 1993, p. 13. En este pasaje cita a BOUDING, K., Organizacional revolution, Chicago, 1953, pp. 179 y sigs.
} 
la necesidad de garantizar un medio ambiente adecuado o de dotar de una vivienda digna a todos los españoles? ¿Justifica el incremento de la productividad una utilización irracional de los recursos naturales?

Fundamentar la oportunidad o no de una intervención pública en la economía sobre los derechos constitucionales precisa de una delicadísima operación tan requerida de técnica jurídica como de realismo valorativo de las circunstancias contextuales. Estará tan influida por el momento histórico, que los factores sociopolíticos prevalecerán sobre los jurídicos. Otra opción, aunque impecablemente razonada en términos científicos, será de cuestionable eticidad. Eso sí, echando mano de la Teoría pura del Derecho kelseniana, se aducirá que una ciencia que tenga por único objeto al Derecho ignora todo lo que no responda estrictamente a su definición y elimina los elementos que le son extraños, especialmente la moral ${ }^{17}$. Permítasenos, empero, la ingenuidad intelectual de defender que el Derecho y la moral han de ser compatibles y que, como señaló RADBRUCH, hay leyes que no son Derecho y Derecho por encima de las leyes. Que - al decir de ENGISCH, HENKEL, PASSERIN D'ENTREVES, POUND, OLLERO TASSARA o DIEZ PICAZO - la eficacia del derecho depende del respeto a una cierta "moralidad pública" o que, parafraseando a SERGIO COTTA, las "valoraciones socialmente dominantes" condicionan tanto la eficacia como la legitimidad del Derecho.

\section{La regulación}

La regulación admite ser contemplada desde tres disciplinas: el Derecho, la Ciencia Política y la Economía ${ }^{18}$. Según la perspectiva que se adopte, será vista como el conjunto de instituciones jurídicas que versan sobre los mecanismos de intervención Estatal para disciplinar todo o una parte del mercado; como la determinación de límites a la libertad de empresa para compatibilizar la eficiencia y el bienestar públicos o como una política pública encaminada a garantizar el interés general en cuyo proceso de implantación juega un papel relevante la negociación entre grupos de interés.

Desde un punto de vista económico, la regulación suele ser vista como una de las formas de intervención del Estado, cardinal para el funcionamiento eficiente de los mercados cuando hay información imperfecta ${ }^{19}$.

El análisis económico establece que los "fallos de mercado" se producen cuando se incumple alguno de los presupuestos de la denominada "competencia perfecta" ${ }^{20}$. Si esto ocurre, la asignación de recursos (producción y consumo) - que resulta de dejar a las empresas y a los consumidores tomar sus decisiones con arreglo a criterios de mercado (sin la

\footnotetext{
${ }^{17}$ KELSEN, H., Teoría pura del Derecho, Universitaria de Buenos Aires, 1989, pp. 15 y sigs.

${ }^{18}$ SPULBER, D. F., Regulation and Markets, MIT Press, Cambridge, 1989.

${ }^{19}$ ALBI, E.; GONZÁLEZ-PÁRAMO, J. y ZUBIRI, I., Economía Pública I, Ariel, Barcelona, 2000, p. 63.

${ }^{20}$ Los supuestos de competencia perfecta son:

$1^{\circ}$. Consumidores y empresas sin capacidad para influir en los precios

$2^{\circ}$. Precios que reflejan toda la información relevante en el mercado

$3^{\circ}$. No existe incertidumbre y todos los agentes disponen de la misma información

$4^{\circ}$. Existen mercados para todos los bienes
} 
intervención pública) — no es eficiente, y, por tanto, es necesario que el Estado actúe para alcanzar un mejor resultado.

Un ejemplo bastante ilustrativo al respecto de lo dicho es el caso de la $\mathrm{I}+\mathrm{D}+\mathrm{i}$. Las inversiones en $\mathrm{I}+\mathrm{D}+\mathrm{i}$ presentan una incertidumbre superior al de otros ámbitos debido al carácter asimétrico de la información. Dicho de otro modo, los inversores no suelen poseer un conocimiento técnico suficientemente preciso del sector como para valorar adecuadamente su actuación. La inversión en $\mathrm{I}+\mathrm{D}+\mathrm{i}$ precisa de unas estimaciones complejas acerca de las posibilidades técnicas del proyecto, el estado de los mercados, los costes de investigación, los costes de producción, los beneficios esperados y la competencia. Ante la deficiencia en la información, los proyectos de este tipo tienen que a hacer frente a condiciones crediticias de elevada exigencia y sus posibilidades de financiación se ven limitadas. La intervención del sector público es crucial para garantizar los fondos necesarios para su desarrollo.

Compartimos la opinión de MALARETI GARCÍA acerca de que la regulación no deja de ser un mecanismo de intervención estatal cuando el mercado falla. Esta inadecuación del mercado como mecanismo de asignación puede por deberse tanto a razones intrínsecas (monopolio natural, bienes públicos, externalidades negativas) como a razones extrínsecas o de equidad u oportunidad política (no de oportunismo político; esto es, entendiendo por oportunidad política la conveniencia de tiempo y lugar para llevar a efecto cierta acción en aras a la satisfacción del interés general) ${ }^{21}$.

En la regulación, el Estado actúa como poder público ejerciendo sus poderes de imperio y justificándose tal intervención en que la eficiencia económica no puede ir en detrimento de la eficaz satisfacción de necesidades colectivas. De ahí la imposición de determinadas obligaciones para garantizar la prestación universal de determinados servicios (servicio universal).

Para MALARETI GARCÍA, la regulación no debe considerarse como una alternativa al servicio público, pues operan en planos distintos. Obedecen a consideraciones de distinta índole, suponiendo una distinta manera de concebir el papel del estado, la estructuración de la vida colectiva y la significación del interés general ${ }^{22}$.

La aseveración de la profesora pone en claro que no se trata de una decisión estrictamente gestora, sino una auténtica decisión de calado político, puesto que derivará de la idea que se tenga del Estado. Utilizando la terminología de ACKERMAN — quien consideró como "Estado activista" el pergeñado por el New Deal de F. D. Roosevelt—, la sustitución del tradicional servicio público por los servicios regulados parte de la concepción de un Estado como "no activista"23. No obstante, el tránsito en la consideración de ciertas actividades como servicios públicos a la de actividad regulada cuestionaría el que no nos hallásemos realmente ante una elección en términos disyuntivos, salvo que el problema radique en el carácter inconcreto del concepto de servicio público al que ya se ha hecho referencia.

\footnotetext{
${ }^{21}$ MALARETI GARCÍA, E., "Regulación económica: su instrumentación normativa”, en Derecho Privado y Constitución, $\mathrm{n}^{\circ}$ 17, enero-diciembre 2003, p. 337.

${ }^{22}$ MALARETI GARCÍA, E., cit., p. 335.

${ }^{23}$ ACKERMAN, B., Social justice in the liberal state, Yale University Press, New Haven, 1980; ACKERMAN, B., Reconstructing american law, Harvard University Press, 1984.
} 
El carácter alternativo de las técnicas no implica la imposibilidad de encontrarlas, de forma simultánea, dentro de un mismo sector, espacio y tiempo. El caso de la educación (aunque resulte discutible y discutida su condición de servicio público) es un paradigma. Aquí se diferenciarían dos espacios: uno sería el ocupado por la intervención directa del Estado, a través de la técnica del servicio público; otro (y porque no se trata de una titularidad pública en exclusiva necesitada de concesión), aquél en el que aparece la iniciativa particular regulada para garantizar estándares mínimos.

En definitiva, la regulación pública pretende sustituir el papel del mercado cuando éste no es capaz de garantizar una eficiente asignación de recursos, pero sin renunciar a la obtención de unos resultados similares, a través de una especie de emulación $^{24}$. En palabras de ALBI:

"Si la actividad del Estado hace posibles los intercambios competitivos, la intervención pública mediante la regulación [...] consigue alterar la asignación competitiva de los recursos sin trastocar el mecanismo básico del mercado. Consumidores y productores privados siguen siendo los protagonistas de las decisiones de producción y de consumo"25.

El Estado-regulador exige una reconsideración de aquello que se encomienda y de lo que se espera de lo público desde una perspectiva, digamos así, reduccionista: abandono de la gestión y concentración en las tareas de reglamentación, de emanación de normas jurídicas.

Mas reconsiderar no es lo mismo que innovar. La regulación es un instrumento que siempre ha estado ahí, porque siempre han existido formas diversas de entender lo que es el Estado y lo que de él se espera. Únicamente si se utiliza el término innovar en su acepción antigua de "volver algo a su anterior estado" sería correcto hablar de la regulación como innovación, pero no si nos referimos a él con su actual significado equivalente a "mudar o alterar algo, introduciendo novedades".

En España han existido, y existen, ciertas actividades en las que las asimetrías informativas para el ciudadano y el especial interés general justificaron la aparición de una regulación; y ello, sin que estimase indispensable la declaración de las mismas como servicio público. Tal es el caso de los "servicios públicos virtuales" o "servicios públicos impropios" $"$.

El Estado-regulador quizás no suponga, pues, un avance del Estado contemporáneo, sino un repliegue del liberalismo hacia a sus cuarteles de invierno, situados en el Estado moderno. A la postre, lo que se reclama es lo que BENJAMIN CONSTANT, allá por el siglo XIX, entendía por "liberté des Modernes"27.

“C'est pour chacun le droit de n'être soumis qu'aux lois, de ne pouvoir être ni arrêté, ni détenu, ni mis à mort, ni maltraité d'aucune manière, par l'effet de la

\footnotetext{
${ }^{24}$ CASSESE, S., "Regolazione e concorenza”, en TESAURO, G. y D'ALBERTI, M. (Dirs.), Regolazione e concorrenza, Mulino, Bologna, 2000.

${ }^{25}$ ALBI, E.; GONZÁLEZ-PẢRAMO, J. y ZUBIRI, I., cit., p. 64.

${ }^{26}$ ARIÑO ORTIZ, G., Principios de derecho público económico, Op. Cit., pp. 503 y sigs.; MEILÁN GIL, J. L., "Sobre la determinación conceptual de la autorización y la concesión", en Revista de Administración Pública, no 71, 1973, pp. 59 a 99.

${ }_{27}$ CONSTANT, B., De la Liberté des Anciens comparée à celle des Modernes, Ecrits politiques, Gallimard, 1997, p. 593.
} 
volonté arbitraire d'un ou de plusieurs individus. C'est pour chacun le droit de dire son opinion, de choisir son industrie et de l'exercer, de disposer de sa propriété, d'en abuser même; d'aller, de venir sans en obtenir la permission, et sans rendre compte de ses motifs ou de ses démarches. C'est, pour chacun, le droit de se réunir à d'autres individus, soit pour conférer sur ses intérêts, soit pour professer le culte que lui et ses associés préfèrent, soit simplement pour remplir ses jours ou ses heures d'une manière plus conforme à ses inclinations, à ses fantaisies. Enfin, c'est le droit, pour chacun, d'influer sur l'administration du Gouvernement, soit par la nomination de tous ou de certains fonctionnaires, soit par des représentations, des pétitions, des demandes, que l'autorité est plus ou moins obligée de prendre en considération”.

\section{SERVICIO PÚBLICO, FUNCIONES DEL ESTADO Y NACIONALIZACIONES}

\section{La azarosa polisemia del término "servicio público"}

Las categorías jurídico-públicas, como lúcidamente ha visto MEILÁN GIL, se prestan a una utilización extrajurídica que los convierte en instrumentos maleables, corriendo el peligro de ser idealizadas, instrumentalizadas y, por ello, adquirir el carácter de mitos ${ }^{28}$.

En el Derecho español del siglo XXI, la voz "servicio público" sigue teniendo un variopinto elenco de significados:

a) A efectos de la responsabilidad patrimonial de las Administraciones Públicas, la Ley 30/1992 sugiere su equivalencia a cualquier actividad administrativa

b) En relación con el dominio público, el artículo 339 del Código Civil lo utiliza como elemento identificador del dominio público y en alternativa al uso público $^{29}$

c) El Código Penal, a la hora de tipificar ciertos delitos (abandono de destino), lo concibe como sinónimo de puesto, dependencia o unidad administrativa ${ }^{30}$

d) El Código Penal Militar, también en el ámbito de la tipificación delictiva, como análogo a cualquier actividad que pueda requerir de la colaboración de las Fuerzas Armadas ${ }^{31}$

\footnotetext{
${ }^{28}$ MEILÁN GIL, J. L., "El servicio público en el derecho actual", en Anuario da Facultade de Dereito, $\mathrm{n}^{\circ}$ 1, Universidade da Coruña, 1997, p. 371.

${ }^{29}$ Artículo 339 del Código Civil: "Son bienes de dominio público:

1. ${ }^{\circ}$ Los destinados al uso público, como los caminos, canales, ríos, torrentes, puertos y puentes construidos por el Estado, las riberas, playas, radas y otros análogos.

2. ${ }^{\circ}$ Los que pertenecen privativamente al Estado, sin ser de uso común, y están destinados a algún servicio público o al fomento de la riqueza nacional, como las murallas, fortalezas y demás obras de defensa del territorio, y las minas, mientras que no se otorgue su concesión".

${ }^{30}$ Artículo 409 del Código Penal: "A las autoridades o funcionarios públicos que promovieren, dirigieren u organizaren el abandono colectivo y manifiestamente ilegal de un servicio público, se les castigará con la pena de multa de ocho a doce meses y suspensión de empleo o cargo público por tiempo de seis meses a dos años".
} 
e) La reciente Ley 11/2007, de 22 de junio, de acceso electrónico de los ciudadanos a los Servicios Públicos, utiliza la expresión para referirse a todo tipo de actividades que la Administración ofrezca a sus ciudadanos

f) En la Ley 19/2013, de 9 de diciembre, de transparencia, acceso a la información pública y buen gobierno, varios artículos utilizan el término "servicio público" en un sentido extraordinariamente amplio. El artículo 4 obliga a las personas físicas y jurídicas que presten servicios públicos o ejerzan potestades administrativas a suministrar a la Administración toda la información necesaria para el cumplimiento de las obligaciones relacionadas con la transparencia; el artículo 8 señala que las Administraciones deberán hacer pública la información estadística necesaria para valorar el grado de cumplimiento y calidad de los servicios públicos que sean de su competencia; el artículo 26 (dedicado a los principios de buen gobierno) indica que las personas comprendidas en su ámbito de aplicación ejercerán sus funciones con dedicación al servicio público, absteniéndose de cualquier conducta que sea contraria a estos principios. En todos preceptos, el término "servicio público" está siendo utilizado con un contenido bien diverso.

Pocos ejemplos servirían, pues, para constatar la ductilidad de la que se ha dotado al concepto de servicio público.

La propia jurisdicción constitucional, cuando se vio obligada a utilizar la institución, no tuvo más remedio que asumir el problema:

"La idea de servicio público no constituye una noción unívoca y sí un concepto muy debatido por la doctrina científica -con detractores y valedores-, sujeto a distintas elaboraciones y utilizado en diversos momentos históricos con finalidades también distintas. Un debate doctrinal en el que no corresponde a un Tribunal Constitucional terciar, so pretexto del ejercicio de su función de control normativo, de no ser inevitable para alcanzar un pronunciamiento de adecuación a la Constitución de la declaración" (STC 127/1994, de 5 de mayo, Fto. Jco. $6^{\circ}$ ).

La doctrina patria ha debatido profusamente acerca de dónde se halla la esencia del servicio público.

El servicio público, desde las posiciones defendidas por VILLAR PALASÍ, se caracteriza por su carácter monopolístico y excluyente, la sumisión a un Derecho exorbitante del común, la regularidad y continuidad en su prestación y, la preexistencia de un derecho abstracto a las prestaciones. Es por esto que insta a reconocer una nueva actividad del Estado (actividad industrial), cuando éste proporciona bienes al mercado sin ajustarse a estas notas ${ }^{32}$.

\footnotetext{
${ }^{31}$ Artículo 153 de la Ley Orgánica 13/1985, de 9 de diciembre, de Código Penal Militar: "El militar que, en el ejercicio de sus funciones, fuere requerido por autoridad competente para la realización de cualquier servicio público en los que puede exigirse legalmente la cooperación de las Fuerzas Armadas y no prestare la que estuviese a su alcance, sin desatender sus deberes preferentes, será castigado con la pena de cuatro meses a cuatro años de prisión".

${ }^{32}$ VILLAR PALASí, L., "La actividad industrial del Estado en el Derecho Administrativo", en Revista de Administración Pública, nº 3, 1950, pp. 53 y sigs.
} 
Tal enfoque es rechazado por otros autores, como GARRIDO FALLA, aduciendo que no todas las características expuestas por VILLAR PALASÍ son cardinales a la hora de concretar el concepto de servicio público ${ }^{33}$. De esta forma, el carácter monopolístico es incuestionable para servicios sin contenido económico, pero no es esencial para todos; la continuidad se compadecería mal con la admisión de la huelga en los servicios públicos; el derecho abstracto a la prestación es predicable de los servicios uti singuli, pero no en los uti universi y, finalmente, el régimen jurídico de exorbitancias respecto al Derecho común no es privativo del servicio público, pues también se halla en algunas formas de gestión económica no incardinables en aquél.

El carácter polifacético de la actividad administrativa y la demostrada polisemia del término "servicio público" abonan la posición de MEILÁN GIL cuando (en su obra La cláusula de progreso en los servicios públicos, publicada a finales de los años sesenta) critica rigurosamente la explicación del servicio público como construcción de fábrica exclusivamente francesa, posteriormente exportada en forma de categoría estática dotada de validez universal ${ }^{34}$.

Los esfuerzos por alcanzar un concepto unívoco y definitivo de servicio público se topan con el inconveniente de que, al decir de MARTÍN REBOLLO, bien podríamos encontrarnos ante una noción inicialmente política y juridificada luego ${ }^{35}$. Por ello, nos quedamos con la afirmación de MEILÁN GIL cuando señala:

"lo característico del servicio público como categoría jurídica diferenciada es su configuración como título habilitante de potestades administrativas, o justificación de la acción del poder público en general si se prefiere”36.

Tal aserción no se encuentra lejana de las posiciones de JÉZE, quien, a la hora de averiguar cómo reconocer la existencia de un servicio público, propone que solamente sean considerados como tales aquellas necesidades de interés general para las que la autoridad haya decidido establecer unas reglas especiales ${ }^{37}$. La presencia de un Estado y el imperativo hacia éste de prestar ciertos servicios se consideran, para JÉZE, causa justificativa de la aparición del Derecho Administrativo. Dado que todo país civilizado tiene servicios públicos y que para el funcionamiento regular de los mismos son necesarias reglas jurídicas ad hoc, en todo país que ha alcanzado la noción de servicio público existirá el Derecho administrativo ${ }^{38}$.

JÉZE niega que sea esencial para la existencia de un servicio público la exclusión de los particulares. La Administración satisface una serie de necesidades de interés general; no obstante, ni asume todas ni en todas las que asume lo hace en régimen de monopolio. Existirán, pues, necesidades satisfechas por la Administración con exclusión de los particulares y otras que lo serán por una actuación conjunta de la

\footnotetext{
${ }^{33}$ GARRIDO FALLA, F., Las transformaciones del régimen administrativo, $2^{\mathrm{a}}$ ed., Instituto de Estudios Políticos, Madrid, 1962, pp. 141 y sigs.

${ }^{34}$ MEILÁN GIL, J. L., La cláusula de progreso en los servicios públicos, Instituto de Estudios Administrativos, Madrid, 1968.

${ }^{35}$ MARTÍN REBOLLO, L., "De nuevo sobre el servicio público: planteamientos ideológicos y funcionalidad técnica", en Revista de Administración Pública, nº 100-102, enero-diciembre 1983, p. 2502.

${ }^{36}$ MEILÁN GIL, J. L., "El servicio público en el derecho actual", Op. Cit., p. 371.

${ }^{37}$ JÉZE, G., Los principios generales del Derecho Administrativo, Reus, 1928 pp. 283 y sigs.

${ }^{38}$ JÉZE, G., cit., pp. 283 y sigs.
} 
Administración y los particulares. Tanto en el caso de prestación excluyente como en el de prestación conjunta, existirán dos procedimientos alternativos a seguir: el procedimiento del Derecho privado y el procedimiento del servicio público. Indicar que existe un servicio público equivaldría, señala JÉZE, a decir que para dar satisfacción regular y continua a cierta categoría de necesidades de interés general existe un régimen jurídico especial y que este régimen puede ser en todo instante modificado por las leyes y reglamentos 39

Descartada la pretensión de encerrar el servicio público en una jaula -y de la que, además, habría escapado antes de cerrarle la puerta-, la única operación intelectualmente honesta es intentar descubrir sus contornos. En este procedimiento de decantación, será preciso procurar su separación de otros conceptos que, aún no pudiendo confundirse con él, se encuentran cercanos.

\section{Funciones del estado y servicios públicos: constitucionalidad versus legalidad}

El profesor MEILÁN GIL ha llamado la atención sobre las consecuencias que tiene para la declaración de servicio público la protección que la Constitución española otorga a los derechos ciudadanos en ella reconocidos. Esta salvaguardia operaría como límite para la iniciativa pública en materia económica $y$, consecuentemente, para la declaración de una actividad como servicio público ${ }^{40}$.

La cuestión tiene especial interés en relación con algunas actividades que han sido consideradas como servicio público por la doctrina y por el legislador. Tal sería el caso de los servicios de carácter asistencial o social, la educación o la televisión.

El contenido del servicio público, señala MEILÁN GIL, es de carácter económico y por ello se advirtió, desde el origen mismo de la institución, la conveniencia de que su gestión fuese encomendada a los particulares (gestión indirecta) fijando una serie de condiciones que garantizasen la rentabilidad (predisposición al establecimiento de monopolios).

Desde esas premisas, el citado autor analiza actividades como las prestaciones sanitarias (artículo 43 de la Constitución Española) o la educación (artículo 27 de la Constitución Española) — que, en la doctrina y, en ocasiones también por el legislador, se denominan "servicios públicos asistenciales" o "servicios públicos objetivos" - para concluir que esa asunción por parte del Estado se realiza en el marco de un Estado social y democrático de derecho y sin necesidad de calificarlas como servicio público en el sentido concreto en el que lo entendió la inicial formulación jurídica de la categoría. No se trata de permitir al Estado que asuma una actividad, sino de una explícita reserva realizada por la Constitución. La obligatoriedad de la afiliación y de las cotizaciones son notas que separan la función del Estado de la idea de servicio público e, incluso, de la más amplia de servicios esenciales. Las prestaciones sanitarias o de educación no pueden entenderse sino como un servicio esencial que el Estado ha de asegurar, cualquiera que sea quién lo preste (el propio Estado o los particulares). El

\footnotetext{
${ }^{39}$ JÉZE, G., cit., p. 284.

${ }^{40}$ MEILÁN GIL, J. L., cit., pp. 383 y sigs.
} 
Estado tiene la exclusiva de la responsabilidad de garantizar la realización de los derechos respectivos, cuya titularidad corresponde a los ciudadanos.

Precisamente porque no se trata de una exclusiva de la titularidad, incompatible con el reconocimiento de los derechos, no existe concesión para que el servicio sanitario (o el educativo) pueda ser prestado por particulares. Se trata de actividades reguladas por el Estado, de conformidad con estándares mínimos determinados por el Estado. De ahí que se utilice la autorización.

El aseguramiento del derecho puede requerir que el Estado realice directamente una actividad administrativa de prestación, como consecuencia normal del compromiso constitucional. Para justificarla, opina MEILÁN GIL, no es necesario acudir a la teoría del "servicio público objetivo".

En esta misma línea, ARIÑO ORTIZ enumera las diferencias entre las actividades consideradas como "funciones públicas del Estado" y las calificables como "servicios públicos"

a) Las funciones del Estado se encontrarían en los fines esenciales del Estado, dentro de su actividad propiamente soberana; mientras que el "servicio público" encuentra su auténtico sentido en la consecución de fines que no constituyen la razón de ser de aquél y, por ello, su titularidad originariamente estuvo en manos de la iniciativa privada, siendo razones coyunturales las que exigieron o permitieron su asunción por el Estado por (insuficiencias en la prestación, incapacidad para la financiación, etc.). Las funciones son esenciales para la vida del Estado, los servicios son indispensables para la vida social.

b) La función pública, dadas su inherencia y esencialidad, son de incuestionable titularidad estatal; es decir, su ejercicio no es susceptible de traspaso a los particulares porque conlleva la utilización de poderes públicos. Por su parte, el servicio público no supone el ejercicio de poderes soberanos, tratándose de prestaciones de índole técnica y perfectamente delegables porque no implican ejercicio inherente a los poderes públicos.

c) La función pública se ejecuta siempre en el marco del Derecho público, mientras que el servicio público puede llevarse a cabo recurriendo al Derecho privado.

d) La función pública es una actividad coactivamente impuesta y que se ejerce a través de actos jurídicos como sentencias, certificaciones, órdenes, etc. El servicio público no se impone, sino que se ofrece. Con ello no se quiere decir que la Administración no pueda ejercitar potestades en este ámbito.

e) La función pública es financiada con cargo a los presupuestos públicos, mientras que las actividades de servicio público son financiadas a través de precios o tarifas.

Una vez fijados los linderos, ARIÑO ORTIZ se encuentra en situación de proponer una definición de servicio público:

\footnotetext{
${ }^{41}$ ARIÑO ORTIZ, G., Principios de Derecho Público Económico, Comares, 1999, pp. 491 y sigs.
} 
“Actividad propia del Estado o de otra Administración pública, de prestación positiva, con la cual, mediante un procedimiento de Derecho público, se asegura la ejecución regular y continua, por organización pública o por delegación, de un servicio técnico indispensable para la vida social”" ${ }^{2}$.

Coincidiendo plenamente con los ilustres maestros, cabe, empero, efectuar una mínima precisión que servirá como primer paso para establecer nuestra postura al respecto de la "teoría de la función pública": la distinción entre Estado y Administración del Estado.

Cuando se señalan como funciones públicas la legislación y la administración de justicia es claro que se asume el hecho de que ambas actividades no corresponden a la Administración del Estado, sino a los poderes legislativo y judicial. La Administración del Estado forma parte, junto al Gobierno, del poder ejecutivo y está muy al margen de poder efectuar cualesquiera de las dos actuaciones mencionadas. Ello conlleva que sea inadecuado referir las funciones estatales a la Administración: debe hacerse a los "poderes del Estado".

Asimismo, tampoco podría admitirse la afirmación de que "la función pública [del Estado] sea ejercida por funcionarios" ${ }^{43}$, dado que el poder legislativo se compone por representantes de los ciudadanos (los empleados públicos de los parlamentos únicamente intervienen en tareas de apoyo) a los que sería impropio calificar de tales (no lo permitiría ni su forma de acceso, ni su régimen jurídico, ni las tareas que tienen encomendadas, ni tan siquiera su régimen de seguridad social), lo adecuado sería decir que "las funciones públicas asumidas por la Administración sólo pueden ser ejercidas por funcionarios públicos".

Todo ello incide en la necesidad de subrayar que las "funciones del Estado" son referibles a los "poderes públicos" (al Estado-organización en su conjunto) y no a las Administraciones públicas (tan solo una parte de la organización estatal).

Asumiendo esta tesis, la inmediata consecuencia es que el señalamiento de tales funciones es cuestión de índole constitucional, ni legal ni administrativa. Primeramente, debido a que se trata de la fundamentación misma del Estado; en segundo lugar, dada la intrínseca relación entre estas funciones y los derechos de los ciudadanos; finalmente, porque el reparto de funciones entre los poderes constituidos es materia típicamente constitucional.

El concepto de Estado no puede ser reducido a una simple formulación jurídica ni cabe tampoco encorsetar sus fines a una inmodificable, atemporal y abstracta enumeración. Si, como se ha señalado reiteradamente por la doctrina, el concepto de servicio público ha evolucionado con los tiempos, no puede negársele a aquél la misma posibilidad.

Como todo significante, presenta un aspecto evolutivo y dinámico sin que ello implique una elasticidad potencialmente restrictiva de los derechos del ciudadano.

\footnotetext{
${ }^{42}$ ARIÑO ORTIZ, G., cit., p. 495.

${ }^{43}$ ARIÑO ORTIZ, G., cit., p. 493.
} 
En nuestra opinión, las diferencias entre funciones del Estado y servicios públicos se reducirían a una: el hecho de que las funciones se encuentren entre los fines esenciales del Estado.

Esta es la realmente importante, pues todas las demás (régimen jurídico, imposición coactiva, traspaso a los particulares o financiación) son accesorias y se justifican por el hecho de que la actividad haya sido declarada inherente a la organización estatal.

Dicho lo anterior ¿cómo explicitar aquéllas actividades inherentes al Estado y conditio sine qua non de su existencia?:

a) De forma expresa, efectuando una directa enumeración de funciones.

b) Tácitamente, por la vía de reconocer al ciudadano ciertos derechos que sólo podrán ser debidamente satisfechos a través de la asunción de una actuación positiva por parte del Estado. Un caso paradigmático es el del artículo 27 de la Constitución española que, al señalar como derecho ciudadano la educación, reclama del Estado proveer lo necesario para ello pueda concretase fácticamente. Lo mismo podría decirse de los artículos 41 (seguridad social), 43 (salud), etc.

En conclusión, a todos los requisitos señalados por la doctrina, y espléndidamente sistematizados por ARIÑO ORTIZ, debería añadirse el que las funciones públicas deben ser identificadas como tales, expresa o tácitamente, por los propios textos constitucionales. Sólo las partes orgánica o dogmática del pacto fundamental resultan ubicación idónea a la hora de señalar las actividades inherentes la organización creada. Por otra parte, resultaría una operación conocida para la norma normarum, pues el propio constituyente previó la asunción ciertas titularidades por parte del Estado; tal es el caso la zona marítimo-terrestre, las playas, el mar territorial y los recursos naturales de la zona económica y la plataforma continental (artículo 132. 2 de la Constitución Española).

Son tan evidentes las razones para reclamar la necesidad de una norma con rango de ley para la publicatio (declaración de una actividad como servicio público) como para defender el rango constitucional de la assumptio (asunción por la organización estatal de actividades consideradas conditio sine qua non de su existencia).

El esclarecimiento de cuál haya sido el motivo de esta ausencia de distinción entre funciones públicas y servicios públicos no resulta sencillo. Quizás pudiera deberse a lo que MEILÁN GIL ha denominado la "multivocidad del término servicio público" y que ha derivado en su capacidad de absorción de otras instituciones jurídicas que, aunque diferentes, presentan grandes similitudes ${ }^{44}$. Quizás fuese consecuencia de lo que LINDE PANIAGUA califica como "tendencia a sacralizar las técnicas e instituciones jurídicas", de forma tal que, aunque que las circunstancias varíen, existe una inveterada y acrítica tendencia a encajar nuevas realidades en antiguos moldes a pesar de que la operación deba efectuarse forzando aquéllas y éstos, con riesgo de fractura para $\operatorname{ambos}^{45}$. Finalmente, tampoco ha de descartarse la existencia de dificultades de relación

\footnotetext{
${ }^{44}$ MEILÁN GIL, J. L., "El servicio público en el derecho actual”, cit., pp. 371 y sigs.

${ }^{45}$ LINDE PANIAGUA, E., "La retirada del estado de la sociedad: privatizaciones y liberalización de servicios públicos", en Revista de Derecho de la Unión Europea, n 7, $2^{\circ}$ semestre de 2004, p. 49.
} 
entre las diversas ramas del Derecho público - en este caso, constitucional y administrativo - derivadas de un tenaz deseo doctrinal de destacar la autonomía de cada una de ellas frente a las demás, cuyo "daño colateral" más evidente sería la imposibilidad de una fluida interconexión.

\section{Diferencias entre "nacionalización" y "declaración de servicio público"}

La delimitación conceptual del servicio público reclama una especial atención en los espacios fronterizos rayanos con las nacionalizaciones.

El consiguiente debate doctrinal se ha contextualizado en el entendimiento del artículo 128.2 de la Constitución Española ("Mediante ley se podrá reservar al sector público recursos o servicios esenciales, especialmente en caso de monopolio y asimismo acordar la intervención de empresas cuando así lo exigiere el interés general"), con la intención de diferenciar entre nacionalización y declaración servicial ${ }^{46}$.

Para unos, la nacionalización supone la asunción por el Estado de la titularidad de un bien o actividad ${ }^{47}$. Esta opción por un concepto lato sensu de nacionalización presenta el inconveniente de difuminar sus diferencias con el de servicio público.

Dados los problemas que la anterior posición plantea, otro sector doctrinal ha apostado por un sentido estricto de nacionalización, proponiendo que se reserve este término para aquellos casos en los que exista una absoluta correlación entre titularidad y gestión. De esta forma, queda reforzada su singularidad respecto al servicio público, el cual, al poder ser concedido a los particulares, no exigiría la gestión directa como conditio sine qua non ${ }^{48}$.

Esta segunda tesis, que defiende la reserva como equivalente a gestión directa, ha sido descartada por el Tribunal Constitucional en base a que, a pesar de que la calificación de "servicio público esencial" se encuentra dentro de las facultades de elección del legislador entre opciones constitucionalmente válidas, ello no significa una habilitación para imponer un injustificado sacrificio de la libertad de empresa (STC 127/1994, de 5 de mayo).

Resulta atinada la preocupación del Tribunal por evitar una limitación innecesaria a la iniciativa privada, pero es necesario sentar que todavía no se ha establecido una diferenciación entre funciones del Estado, servicios públicos y servicios nacionalizados en la jurisprudencia constitucional. De esta forma, no resulta factible

\footnotetext{
46 MARTÍN REBOLLO, L., "De nuevo sobre el servicio público: planteamientos ideológicos y funcionalidad técnica", en Revista de Administración Pública, n 100-102, enero-diciembre 1983, pp. 2512 y 2513.

${ }^{47}$ MARTÍN MATEO, R., Ordenación del sector público en España, Civitas, Madrid, 1973; MARTÍN MATEO, R. y SOSA WAGNER, F., Derecho Administrativo Económico. El Estado y la empresa, $2^{\mathrm{a}}$ ed., Pirámide, Madrid, 1977.

${ }^{48}$ FERNÁNDEZ FARRERES, G. J., Libertad de empresa y nacionalizaciones, Cuadernos aragoneses de economía, No 3, 1978-1979 , pp. 217-226; ARIÑO ORTIZ, G., "La empresa pública”, en GARRIDO FALLA, F., El modelo económico en la Constitución española, vol. II, Instituto de Estudios Económicos, Madrid, 1981.
} 
recurrir a ella para encontrar unas características básicas de la nacionalización que la diferencien de las otras dos instituciones.

Por otra parte, la circunstancia de que exista un régimen de monopolio del sector público no exige necesariamente que la gestión sea directa. Lo que excluye es que esta misma actividad se preste por el sector privado en concurrencia con el sector público. Es decir, se trata de vedar un ámbito a la libre iniciativa privada. Nada más. Con tal de que se esté en presencia de una actividad con contenido económico que la haga susceptible de explotación (a riesgo y ventura del contratista), nada impide que su desarrollo efectivo pueda ser deferido a empresas privadas. No se trata de una función pública y, por ello, no es exigible la prestación directa.

En este sentido, cabe recordar que el artículo 277 del Real Decreto Legislativo $3 / 2011$, de 14 de noviembre, por el que se aprueba el texto refundido de la Ley de Contratos del Sector Público, al enumerar las modalidades que podrá adoptar la contratación de la gestión de los servicios públicos, sólo exigiría que la actividad estuviese abierta a la empresa privada en el caso del concierto (dado que pretende que éste se haga con persona natural o jurídica que venga realizando prestaciones análogas a las que constituyen el servicio público de que se trate, algo que sería impensable sin que la actividad estuviese abierta a la libre iniciativa), pero no para el caso de la concesión, cuyo único requisito es que el empresario pueda gestionar el servicio a su propio riesgo y ventura (que la actividad tenga un contenido susceptible de explotación económica rentable).

Se nos antoja plausible la postura de MARTÍN REBOLLO cuando sostiene que, excepción hecha de la planificación y la iniciativa pública en materia económica, la única técnica de cercenamiento del mercado (en sectores concretos) está en la previsión del artículo 128.2 de la Carta Magna y que declaración servicial y nacionalización, en sus efectos prácticos, vendrían a ser la misma cosa. No obstante, disentimos en la apreciación de que el servicio esencial al que este precepto apela no pueda ser concedido ni gestionado por particulares ${ }^{49}$.

La inteligencia del artículo 128.2 como opción del legislador para someter "algunos servicios esenciales" a un régimen especial obliga a reconocer que no se está refiriendo a "todos los servicios esenciales". No todos los servicios públicos son reconducibles al artículo 128.2, sólo aquéllos que el sector público decida reservarse, de forma excepcional y en régimen monopólico, para sí. Esta iniciativa del legislador sólo estaría limitada, a nuestro entender, por el hecho de que la Constitución sugiere la actuación positiva "especialmente en caso de monopolio". La forma más adecuada de interpretar esta última afirmación pasa por reconocer que, en el ámbito de los monopolios naturales (actividades que, por naturaleza, sólo admiten este régimen), el interés general y los derechos constitucionales de los ciudadanos aconsejarían una actitud pro-nacionalización en orden a evitar los posibles abusos de una posición de absoluto dominio del mercado. Sin imponer una decisión concreta, se indica un ámbito al que hay que prestar especial atención y para el que la figura de la nacionalización parece una solución razonable.

\footnotetext{
49 MARTÍN REBOLLO, L., "De nuevo sobre el servicio público: planteamientos ideológicos y funcionalidad técnica", cit., p. 2516.
} 
La razón de la reserva material de ley para las declaraciones serviciales no deriva del artículo 128.2 de la Constitución, sino de los límites que éstas imponen a la libertad de empresa. Como destacó DE LA CUÉTARA, el constituyente español dotó a la libertad de empresa de una "garantía institucional" consistente en defender la institución en sí (no todas y cada una de sus manifestaciones, susceptibles de mudanza por su carácter contingente), siendo la iniciativa pública perfectamente admisible, siempre y cuando la situación contextual sea calificable de una auténtica economía de mercado $^{50}$.

La no admisión de servicios públicos al margen del artículo 128.2 cercenaría de forma innecesaria e improcedente las posibilidades de actuación del Estado social. Amén de esto, se dejaría un reducidísimo espacio para la institución de la regulación económica y la imposición de "obligaciones de servicio público", pues en los servicios públicos no nacionalizables (por no esenciales), lo que importa no es la titularidad del Estado (pues admiten la gestión privada), sino su control y supervisión.

El cercenamiento del Estado social sería innecesario porque la indeterminación del término "esencial" acabaría dejando en manos del legislador de turno la definitiva integración del mismo. Se trataría de un viaje a ninguna parte.

La improcedencia del cercenamiento derivaría de tratarse de una determinación a posteriori de un modelo económico que el constituyente dejó en deliberada imprecisión. Cierto que la Constitución Española de 1978 -especialmente en su contenido económico- es ambigua y ha de ser interpretada, pero esto no conlleva la eliminación de la ambigüedad, sino la penetración en su auténtico sentido y utilidad. Durante el proceso de elaboración constitucional, la necesidad de construir un texto en el que cupiesen muy heterogéneas concepciones -en el marco de una imposibilidad de compromiso definitivo sobre ciertos temas- encontró una atinada solución en la utilización de fórmulas lo suficientemente ambiguas como para permitir una interpretación desde el poder. Así lo han evidenciado, entre otros, HERRERO DE MINÓN, HERNÁNDEZ GIL, RUBIO LLÓRENTE y ARAGÓN REYES ${ }^{51}$.

La ambigüedad ha sido en el fundamento del consenso constituyente español y es difícil aventurar hasta qué punto no pueda seguir siendo fundamento del consenso constitucional.

\section{Funciones del estado, servicios públicos y nacionalizaciones}

Como recapitulación de lo expuesto en las líneas precedentes, a la hora señalar linderos entre funciones del Estado, servicio público y servicios nacionalizados, cabría proponer la siguiente diferenciación:

\footnotetext{
${ }^{50}$ DE LA CUÉTARA, J. M., La actividad de la Administración, Madrid, 1983, pp. 226 y 227.

${ }^{51}$ Al respecto de las razones de la ambigüedad del texto constitucional español, vide: HERRERO DE MIÑÓN, M., "Falsas y verdaderas vías del consenso constitucional”, en Revista de Estudios Políticos, Centro de Estudios Políticos y Constitucionales, nº 9, mayo-junio 1979, pp. 73 a 97; HERNÁNDEZ GIL, A.: "Neutralidad y consenso", en Constitución, economía y regiones, tomo III, Club Siglo XXI, Madrid, 1978, pp. 666 y sigs.; RUBIO LLÓRENTE, F. y ARAGÓN REYES, M.: "Enunciados aparentemente vacíos en la regulación constitucional del control de constitucionalidad", en Revista de Estudios Políticos, Centro de Estudios Constitucionales, nº 7, enero-febrero 1979, pp. 161 a 169.
} 
a) Las "funciones del Estado" son, por definición, de obligatoria asunción para el Estado por mandato constitucional (assumptio), pero no todas ellas reclamarían una exclusión de su prestación por los particulares, siempre que cumplan unos requisitos mínimos controlables a través de la actividad administrativa de policía (caso de la educación, señalado por MEILÁN GIL). Sólo estarían exceptuadas de este régimen concurrencial, las actividades que conlleven ejercicio de autoridad inherente a los poderes públicos (defensa nacional, seguridad pública,...)

b) Las actividades de "servicio público" son aquellas que así se declaran por ley (publicatio). Por regla general, son susceptibles de prestación tanto indirecta como directa y en concurrencia con los particulares. Como en el caso de las funciones del Estado, estarían exceptuadas del régimen de concurrencia las actividades que conlleven ejercicio de autoridad inherente a los poderes públicos

c) La "nacionalización de servicios" se constituye como una reserva de servicios públicos esenciales (aunque no todo servicio esencial tenga que ser nacionalizado, pues la Constitución dice que "se podrá" reservar al sector público recursos o servicios esenciales) que excepciona la libertad de empresa (se establece un régimen de monopolio a favor del Estado), pero no impide su gestión indirecta siempre que sus características lo permitan (susceptibilidad de explotación económica). La nacionalización no supone de iure, ni debiera hacerlo de facto, la asunción de nuevas funciones por parte del Estado. Esta cuestión no es de índole legislativa o administrativa, sino constitucional.

\begin{tabular}{|c|c|c|}
\hline & Declaración & Régimen de prestación \\
\hline $\begin{array}{l}\text { Función del } \\
\text { Estado }\end{array}$ & $\begin{array}{l}\text { Base constitucional } \\
\text { (assumptio) }\end{array}$ & $\begin{array}{l}\text { Obligatoria para el Estado (poderes } \\
\text { legislativo, judicial o ejecutivo), } \\
\text { pero admitiendo concurrencia con } \\
\text { los particulares, salvo que conlleven } \\
\text { ejercicio de la autoridad inherente a } \\
\text { los poderes públicos (defensa } \\
\text { nacional, seguridad pública,...) }\end{array}$ \\
\hline Servicio público & Por ley (publicatio) & $\begin{array}{l}\text { Obligatoria para la Administración. } \\
\text { Admite la iniciativa privada, salvo } \\
\text { que conlleven ejercicio de la } \\
\text { autoridad inherente a los poderes } \\
\text { públicos }\end{array}$ \\
\hline $\begin{array}{l}\text { Nacionalización } \\
\text { de servicio }\end{array}$ & $\begin{array}{l}\text { Por ley, en base al } \\
\text { artículo } 128.2 \text { de la CE } \\
\text { (publicatio) }\end{array}$ & $\begin{array}{l}\text { Obligatoria para la Administración. } \\
\text { Régimen de monopolio. No admite } \\
\text { la libre iniciativa privada, pero cabe } \\
\text { la gestión indirecta si es susceptible } \\
\text { de explotación económica y no } \\
\text { conlleva ejercicio de la autoridad } \\
\text { inherente a los poderes públicos }\end{array}$ \\
\hline
\end{tabular}


En la averiguación de qué prestaciones resultan esenciales para la colectividad, debería jugar un papel relevante el artículo 9 de la Constitución Española, de tal forma que la esencialidad estaría relacionada con la necesidad de garantizar las condiciones adecuadas para que la igualdad, la libertad y la participación (política, económica, cultural y social) de los ciudadanos fuesen efectivas.

Este precepto se elevaría a "cláusula de habilitación" para el poder público. De hecho, el propio Tribunal Constitucional ha admitido que el artículo 9.2 impone, sin duda, actuaciones positivas (STC 6/81, de 16 de marzo), siendo ambas cosas obligación y positividad — características del servicio público.

\section{La crisis del servicio público puede ser simple apariencia}

La pretensión de considerar la existencia de servicios públicos regidos por el Derecho privado como justificación de la imposibilidad de caracterizar al Derecho administrativo como el Derecho regulador de los servicios públicos carece de cierta solidez.

Los servicios públicos requieren de una expresa declaración por Ley, la cual establecerá las bases de un régimen jurídico compuesto por normas de Derecho público. Otra cuestión es que el desempeño de la actividad se lleve a cabo desde normas de Derecho privado.

Para confirmar este punto, trasladémonos al plano organizativo. Nadie dudó sobre el carácter público de las entidades públicas empresariales creadas por la Ley 6/1997, de 14 de abril, de Organización y Funcionamiento de la Administración General del Estado (de cuyos artículos 42 y 43 cabe deducir, inequívocamente, su calificación como entes públicos); sin embargo, el artículo 53 de la mencionada ley reconoció que "se rigen por el Derecho privado, excepto en la formación de la voluntad de sus órganos, en el ejercicio de las potestades administrativas que tengan atribuidas y en los aspectos específicamente regulados para las mismas en esta Ley, en sus estatutos y en la legislación presupuestaria". Lo que determina el carácter público de estas organizaciones es el hecho de haber sido creadas por un acto de Derecho público y estar configuradas —en sus competencias, potestades y control— por normas de Derecho público.

De vuelta de nuevo al tema principal, esto mismo es lo que caracteriza al servicio público, con independencia del régimen jurídico elegido para el desempeño concreto de la prestación. Lo trascendental es la configuración de cómo se llevará a efecto la actividad, en vez de la concreta ejecución de ésta.

La reducción de la esencialidad del servicio público a su condición de título habilitante de potestades administrativas (como propone MEILÁN GIL) —o, dicho de otra forma, la concepción de éste como necesidades de interés general para cuya satisfacción la autoridad haya optado por un régimen jurídico especial y exorbitante del Derecho privado (como plantea JÉZE) — permite enfocar mejor la cuestión y reconocer que la regulación (compuesta por normas del Derecho público) no es más que una forma de contemplar el servicio público. Con ello, se incide en una forma de entender el Derecho administrativo en la línea de lo que preconizó MARTÍN MATEO (y entendemos que desde una similar posición a MEILÁN GIL, para el que lo sustantivo 
de la caracterización del Derecho administrativo es antes el interés general que la Administración personificada), quien, sin dejar de reconocer a la Administración como natural destinataria de éste, lo definiría como el "Derecho que regula el ejercicio de actividades dirigidas a finalidades de interés público, para cuya consecución el Ordenamiento concede potestades singulares"

Admitiendo esta tesis, cabe concluir que las formas de entender el servicio público realmente no son más que la concreción del papel que se quiera otorgar al sector público en la economía:

a) Servicio público con posición activa del sector público (configuración socializante)

b) Servicio público como regulación (punto de vista liberal)

Ambas perspectivas se compadecen perfectamente con el Estado de Derecho y con el Estado democrático; no obstante, la compaginación del Estado social con la regulación, sin ser de ningún modo insostenible, exige una especial habilidad política, jurídica y moral.

El esquema básico de la regulación y su expansión no romperán con la esencia de la definición del servicio público si se toma ésta en la forma propuesta por MEILÁN GIL, esto es, como un régimen de Derecho público. Es más, la extensión del modelo de regulación coincidiría con los postulados de este autor, para quien el Derecho administrativo no es esencialmente un Derecho estatutario, sino un Derecho que regula los intereses generales. Extendiendo la regulación, se amplía el ámbito de actuación de los particulares y los supuestos de aplicación del Derecho administrativo como regulador de una actividad en cuanto esté dirigida a la satisfacción del interés público ${ }^{53}$.

Las crisis del servicio público, por tanto, son sólo aparentes. Lo único que puede estar en situación crítica es una concreta forma de entender el papel desempeñado por el Estado.

Puede sostenerse que el término servicio público se refiere únicamente a la utilización del Derecho público en relación con una serie de actividades calificadas legalmente como tales y con todas las ventajas e inconvenientes que ello conlleva. La cuestión de si ello se materializará a través prioritariamente de la potestad normativa o mediante actuaciones positivas concretas de la Administración es algo que dependerá del modelo económico por el que se opte.

Dicho lo anterior, hay motivos para dudar acerca de si todavía existen alternativas (a nivel nacional) para la elección en momentos históricos caracterizados por las fuertes restricciones presupuestarias y las presiones - de hecho y de Derecho- que ejercen las organizaciones internacionales de integración (caso de la Unión Europea).

La Constitución Española, hasta fechas recientes, se había decantado por dejar inconcreto el modelo económico y abandonarlo a una "interpretación desde el poder". Tras su última reforma, con la modificación del artículo 135, la cuestión parece haber cambiado, viéndose reducidas la capacidad de elección. El cercenamiento de las opciones de endeudamiento para sufragar las políticas sociales coloca a un lado de la balanza el artículo $135 \mathrm{y}$, al otro, los derechos de carácter prestacional. El punto de equilibrio se habría

\footnotetext{
${ }^{52}$ MARTÍN MATEO, R., "La sustantividad del Derecho administrativo, en Revista de Administración Pública, no 53, 1967, pp. 35 a 71.

${ }^{53}$ MEILÁN GIL, J. L., Categorías jurídicas en el Derecho Administrativo, Iustel, Madrid, 2011.
} 
desplazado hacia el artículo 31 de la Carta Magna: siendo exiguas las posibilidades de recurrir a la deuda pública, sólo restaría o una "mayor presión fiscal- mayor actividad prestacional" o una "menor presión fiscal- menor actividad prestacional".

A pesar de las apariencias, no es tan obvio que el camino sólo se bifurque. Existe un tercer sendero por recorrer. Lejos de imponer una visión unidireccional del modelo económico, la nueva redacción del artículo 135 quizás haya abierto, por vía oblicua, una nueva razón para justificar la intervención del Estado en la actividad económica y servicial. Y ello es así porque existe una fuente alternativa de ingresos estatales de carácter extrafiscal: la explotación (gestión económica, no enajenación) del patrimonio público (bienes patrimoniales y demaniales) y la optimización de la gestión de aquellas actividades de contenido económico que venga desempeñando el sector público. No obstante ¿existe el riesgo de erigir un "Estado empresario" en detrimento de la competencia? El ordenamiento jurídico nacional e internacional permiten imaginarlo impracticable $\mathrm{y}$, por otra parte, tanto desasosiego produce pensar en un Estado que actúe a favor de sus empresas y contra del resto del mercado (de lo cual todos saldrían perjudicados), como que, en una situación de nula intervención pública económica, el Estado favorezca a empresas próximas a los miembros del Gobierno. Ambas situaciones son posibles. La obligación de un Estado de Derecho es establecer los mecanismos de control que permitan hacerlas altamente improbables.

\section{Llegados a este punto, procede recordar las palabras de MARTÍN REBOLLO:}

"El prejuicio frente a la actividad empresarial del Estado no puede ser ya ideológico. Todos los Gobiernos de uno u otro signo mantienen, ciertamente con mayor o menor amplitud, un sector público cuyo volumen es de todas formas considerable. Y, además, en las condiciones actuales, es impensable que fuera de otra manera. Así pues, si superamos los mitos y los tópicos, el debate será más razonable y se centrará en los aspectos que más interesan y que en buena medida no son cuestiones jurídicas propiamente hablando: la oportunidad, la eficacia, la operatividad, la profesionalización, la tecnificación, la experiencia práctica real. El Estado gestionando directamente por el mero hecho de ser Estado —al margen ahora de otras consideraciones sociales y de interés público que, con todo, no deben abandonarse - no lo hace mejor, no es mejor empresario que un particular, pero tampoco a la inversa absoluta y necesariamente. Dependerá también de qué Estado, de qué Gobierno, de qué personas, de qué profesionales, de qué empresarios",54.

El Estado debe dejar de ser mero espíritu (consecuencia exclusiva e incuestionable de una historia y unos éxitos ya pretéritos) para encarnar en garante de un proyecto e intereses comunes y actuales de sus ciudadanos. Si no es eso, sobre todo en circunstancias difíciles, correrá el riesgo de no ser nada. Sobre ello alertaba DUGUIT.

Hasta el propio HEGEL, reconociendo a su "supremo organismo ético" una serie de insuficiencias, advierte que el Estado existe cuando, en el seno de la colectividad, cada ciudadano encuentra satisfacción de los intereses que reconoce como razonables. Ello equivale a reivindicar que la separación entre ese "universal pensado" y el estado real de la sociedad no sea demasiado flagrante. En caso contrario, el individuo se resistirá a reconocer

\footnotetext{
54 MARTÍN REBOLLO, L., "De nuevo sobre el servicio público: planteamientos ideológicos y funcionalidad técnica", cit., p. 2524.
} 
una sociedad que le niega la satisfacción de sus necesidades. El pueblo ha de reconocerse en el Estado ${ }^{55}$.

\section{CONCLUSIONES}

En relación con las controversias, y desmarcándose de los sofistas, decía DIDEROT —en crítica a las confrontaciones entre los enciclopedistas y sus detractores - que aquéllas se eternizan cuando los dos adversarios se sirven de las mismas palabras con sentidos diferentes. En similar posicionamiento, DESCARTES planteó lo indispensable que resulta empezar la discusión definiendo los términos del debate y la exacta significación de las palabras.

Desde la Ciencia del Derecho (la jurisprudencia, en el sentido más literal del término), NORBERTO BOBBIO (fundador de la "Escuela de Turín" y uno de los más afamados representantes de la "dirección analítica" del positivismo jurídico) señaló que el discurso científico debe ser ante todo riguroso y que, para la ciencia, lo decisivo no es tanto la verdad como el rigor. La cientificidad de un discurso no consiste en la verdad (en la correspondencia de la enunciación con una realidad objetiva), sino en el rigor de su lenguaje. De ahí que la jurisprudencia sea -en su más parte esencial- un análisis del lenguaje y, de modo más preciso, de ese específico lenguaje en el que a través de las proposiciones normativas se expresa el legislador. La tarea de la ciencia del Derecho sería, pues, depurar y clarificar el lenguaje del legislador para convertirlo en un lenguaje riguroso. Según BOBBIO, se pueden distinguir tres fases en la jurisprudencia: fase de purificación (en la que se transforma el lenguaje del legislador en un lenguaje riguroso), fase de integración (momento en el que el jurista completa el lenguaje del legislador) y fase de ordenación (reducción del lenguaje del legislador a sistema).

Los distintos investigadores que han profundizado en la teoría de la argumentación jurídica se adhieren a la idea de una depuración del lenguaje jurídico. Tal es el caso de autores como ROBERT ALEXY (quien, dentro de las reglas fundamentales del discurso, incluye la necesidad de que distintos hablantes no puedan usar la misma expresión con distintos significados), AULIS AARNIO (considerando la utilización de un lenguaje común como condición indispensable del consenso) o nuestro compatriota MANUEL ATIENZA.

Dicho lo anterior ¿Por qué la legislación española ha definido obra pública y dominio público en tanto que el concepto de servicio público ha quedado huérfano a este respecto? ¿Por qué la Unión Europea ha considerado pertinente aclarar los conceptos de servicio público, servicio de interés económico y servicio universal, mientras que en España no se ha dedicado una ley a regular los aspectos más generales de la institución del servicio público? ¿Cuál ha sido la justificación del abandono de esta tarea a la doctrina y la jurisprudencia? ¿Cómo es posible que se explicite legislativamente el concepto de todas y cada una de las formas de prestación indirecta de los servicios públicos sin una previa definición de lo que éstos son? ¿Por qué dejar al Parlamento el señalamiento de una actividad como servicio público sin prefijar unos parámetros claros que permitan evaluar su decisión? Cierto que, en buena medida, esto

\footnotetext{
${ }^{55}$ TOUCHARD, J., Historia de las ideas políticas, Tecnos, $6^{\text {a }}$ ed., 2ª reimpresión, Madrid, 2008, pp. 390 y 391.
} 
resultaría un ejercicio de autolimitación, pero intuimos que se trata de algo más que eso. Se estaría proveyendo de rigor al marco jurídico en el que debe actuar la Administración. Bastaría con echar un vistazo a los informes de la Junta Consultiva de Contratación Administrativa estatal para darse cuenta de las numerosas ocasiones en las cuales las Administraciones Públicas (especialmente la local) se han dirigido a este órgano para cerciorarse de si la gestión que venían realizando de algunas actividades (en base a su consideración o no como servicio público) era correcta (algunas de un carácter tan chusco como las relativas a las cafeterías instaladas en dependencias administrativas abiertas al público).

Aún a riesgo de perder el esplendor de encendidos debates doctrinales, entendemos que sería muy conveniente que el ordenamiento patrio procediese a positivizar normativamente los conceptos de servicio público, servicio de interés general, funciones esenciales del Estado y nacionalización.

Cuando el jurista ingles JOHN LANSHAW AUSTIN —en How to do things with words? (1962) — afirmó que todo lenguaje es ejecutivo y está hecho de "actos de palabras", se estaba refiriendo a que la elocución (manera de hablar para expresar los conceptos) no sólo describe la realidad, sino que tiene un efecto sobre ella. Las palabras y el significado que se les otorgue construyen la realidad, no la relatan.

Para "neutralizar un término", nada mejor que no dotarle de un contenido concreto. Si bien el carácter "abierto" de los textos constitucionales puede dotar a éstos de una mayor permanencia en el tiempo, hacer lo mismo con las normas administrativas es abonar su inoperancia; algo similar a lo que sugería NIETO refiriéndose a la infiltración en las leyes de preceptos, engañosamente imparciales y justos, cuya aplicación no es peligrosa para determinados grupos de la comunidad al no resultar operativa.

Compartimos, con MEILÁN GIL, la crítica hacia una concepción estática del servicio público ${ }^{56}$, pero esta misma posición - de descarte del estatismo- compromete a no dar por superada la institución. Su capacidad para evolucionar es, precisamente, lo que favorece la adaptación a los diversos avatares y garantiza su pervivencia en el tiempo.

\section{BIBLIOGRAFÍA}

ACKERMAN, B., Social justice in the liberal state, Yale University Press, New Haven, 1980.

ACKERMAN, B., Reconstructing american law, Harvard University Press, 1984.

ALBI, E.; GONZÁlEZ-PÁRAMO, J. y ZUBIRI, I., Economía Pública I, Ariel, Barcelona, 2000.

ARIÑO ORTIZ, G., Principios de Derecho Público Económico, Comares, 1999.

\footnotetext{
56 MEILÁN GIL, J. L., La cláusula de progreso en los servicios públicos, Instituto de Estudios Administrativos, Madrid, 1968.
} 
ARIÑO ORTIZ, G., "La empresa pública", en GARRIDO FALLA, F., El modelo económico en la Constitución española, vol. II, Instituto de Estudios Económicos, Madrid, 1981.

ATIENZA, M., El sentido del Derecho, Ariel, Barcelona, 2001.

CASSESE, S., "Regolazione e concorenza”, en TESAURO, G. y D'ALBERTI, M. (Dirs.), Regolazione e concorrenza, Mulino, Bologna, 2000.

DE LA CUÉTARA, J. M., La actividad de la Administración, Madrid, 1983.

DUVERGER, M., Les Régimes politiques, Presses Universitaires de France, 1948.

EASTON, D., The Political System: An Inquiry Into the State of Political Science, Knopf, 1953

FERNÁNDEZ FARRERES, G. J., Libertad de empresa y nacionalizaciones, Cuadernos aragoneses de economía, No 3, 1978-1979.

GABRIEL, A. y POWELL, G., Comparative Politics, a developmental approach, Boston, MA, Little Brown, 1966.

GARCÍA PELAYO, M., Las transformaciones del Estado contemporáneo, Alianza, $2^{\mathrm{a}}$ ed., 1993.

GARRIDO FALLA, F., Las transformaciones del régimen administrativo, $2^{\mathrm{a}}$ ed., Instituto de Estudios Políticos, Madrid, 1962.

HERRERO DE MIÑÓN, M., "Falsas y verdaderas vías del consenso constitucional”, en Revista de Estudios Políticos, Centro de Estudios Políticos y Constitucionales, no 9, mayo-junio 1979.

HERNÁNDEZ GIL, A.: "Neutralidad y consenso", en Constitución, economía y regiones, tomo III, Club Siglo XXI, Madrid, 1978.

HOPPE, H., "Falacias de la teoría de los bienes públicos y la producción de seguridad", en Procesos de Mercado, $\mathrm{n}^{\circ}$ 1, 2007.

JÉZE, G., Los principios generales del Derecho Administrativo, Reus, 1928.

KELSEN, H., Teoría pura del Derecho, Universitaria de Buenos Aires, 1989.

LINDE PANIAGUA, E., "La retirada del estado de la sociedad: privatizaciones y liberalización de servicios públicos", en Revista de Derecho de la Unión Europea, n 7 , $2^{\circ}$ semestre de 2004 .

MADDALA, G.S. y MILLER, E., Microeconomía, Ed. McGraw-Hill, México, 1996.

MALARETI GARCÍA, E., "Regulación económica: su instrumentación normativa”, en Derecho Privado y Constitución, $\mathrm{n}^{\circ}$ 17, enero-diciembre 2003.

MARTÍN MATEO, R., "La sustantividad del Derecho administrativo, en Revista de Administración Pública, nº 53, 1967, pp. 35 a 71.

MARTÍN MATEO, R., Ordenación del sector público en España, Civitas, Madrid, 1973

MARTÍN MATEO, R. y SOSA WAGNER, F., Derecho Administrativo Económico. El Estado y la empresa, 2a ed., Pirámide, Madrid, 1977.

MARTÍN MATEO, R. y SOSA WAGNER, F., Derecho Administrativo Económico. El Estado y la empresa, 2a ed., Pirámide, Madrid, 1977. 
MARTÍN REBOLLO, L., "De nuevo sobre el servicio público: planteamientos ideológicos y funcionalidad técnica", en Revista de Administración Pública, n 100-102, enero-diciembre 1983.

MEILÁN GIL, J. L., Categorías jurídicas en el Derecho Administrativo, Iustel, Madrid, 2011.

MEILÁN GIL, J. L., La cláusula de progreso en los servicios públicos, Instituto de Estudios Administrativos, Madrid, 1968.

MEILÁN GIL, J. L., "El servicio público en el derecho actual", en Anuario da Facultade de Dereito, n $^{\circ}$ 1, Universidade da Coruña, 1997.

NOZICK, R., Anarquía, estado y utopía, Fondo de Cultura Económica, 1990.

QUERMONNE, J. L., Les régimes politiques occidentaux, Éditions du Seuil, 2000.

RAWLS, J., A theory of Justice, Oxford, 1971.

RUBIO LLÓRENTE, F. y ARAGÓN REYES, M.: "Enunciados aparentemente vacíos en la regulación constitucional del control de constitucionalidad", en Revista de Estudios Políticos, Centro de Estudios Constitucionales, nº 7, enero-febrero 1979.

SAMUELSON, P. A. y NORDHAUS, W. D., Economía, 12ª Ed., Mc Graw Hill.

SANTIAGO NINO, C., Introducción al análisis del Derecho, $7^{\mathrm{a}}$ ed., Ariel, Barcelona.

SCHNERB R. y DUVERGER, M., "Les régimes politiques", en Annales. Économies, Sociétés, Civilisations, vol. 4, n 3, 1949.

SPULBER, D. F., Regulation and Markets, MIT Press, Cambridge, 1989.

STIGLITZ, J. E., La economía del sector público, $3^{\text {a }}$ ed., Antoni Bosch, 2000, pp. 149 a 178.

TOUCHARD, J., Historia de las ideas políticas, Tecnos, $6^{\mathrm{a}}$ ed., $2^{\mathrm{a}}$ reimpresión, Madrid, 2008.

VILLAR PALASÍ, L., "La actividad industrial del Estado en el Derecho Administrativo", en Revista de Administración Pública, nº 3, 1950. 